\title{
"Shake It Baby, Shake It": Media Preferences, Sexual Attitudes and Gender Stereotypes Among Adolescents
}

\author{
Tom F. M. ter Bogt • Rutger C. M. E. Engels • \\ Sanne Bogers • Monique Kloosterman
}

Published online: 27 August 2010

(C) The Author(s) 2010. This article is published with open access at Springerlink.com

\begin{abstract}
In this study exposure to and preferences for three important youth media (TV, music styles/music TV, internet) were examined in relation to adolescents' permissive sexual attitudes and gender stereotypes (i.e., views of men as sexdriven and tough, and of women as sex objects). Multivariate structural analysis of data from a school-based sample of 480 13 to 16-year-old Dutch students revealed that preferences, rather than exposure were associated with attitudes and stereotypes. For both girls and boys, preferences for hip-hop and hard-house music were associated positively with gender stereotypes and preference for classical music was negatively associated with gender stereotypes. Particularly for boys, using internet to find explicit sexual content emerged as a powerful indicator of all attitudes and stereotypes.
\end{abstract}

Keywords Adolescents · Sexual attitudes · Music · Music television · Pornography · Internet

\section{Introduction}

Over the last three decades research has found that media entertainment affects the development of sexual attitudes

T. F. M. ter Bogt $(\bowtie)$

Department of Interdisciplinary Social Science,

University Utrecht,

PO Box 80140, 3584 CS Utrecht, The Netherlands

e-mail: t.f.m.terbogt@uu.nl

R. C. M. E. Engels

Behavioral Science Institute, Radboud University,

Nijmegen, The Netherlands

S. Bogers $\cdot$ M. Kloosterman

Utrecht University,

Utrecht, The Netherlands among adolescents. While young people, to a certain extent, acquire knowledge of sexuality from their parents, and even more so, from their same-sex peers (e.g., Handelsman et al. 1987), the media has been identified as an important source of knowledge for the physical, social, and emotional aspects of dating, romance, and sex (e.g., Brown et al. 2005; Christenson et al. 2004). In general, young people turn more readily to media that presents 'forbidden fruits' in a far more overt, detailed, and appealing way than most parents or educators offer (Sutton et al. 2002). Youth oriented entertainment media including movies, TV, magazines, pop music, and music videos are targeted at a teenage audience and provide a vast array of messages on falling in love, relationships, and sexual desires; therefore, may shape sexual attitudes, values, and practices. The internet, with its easy access and highly explicit sexual content, has become another important source of information (Lo and Wei 2005; Peter and Valkenburg 2006a; Strasburger and Donnerstein 1999; Wolak et al. 2007).

Media may present a rather unrealistic and skewed account of human romance and sexuality leading some commentators to raise concerns that youth media, with their formulaic portrayal of gender roles and sexuality, is developing and sustaining stereotypical gender-role schemas; for example, ideas that, for women, looks and sexiness are all important and, for men, sexual obsession is normal, and sexual prowess an asset (e.g., Ward 2002). Negative correlates and consequences of (sexualized) gender stereotyping have been shown to range from confining females and males into traditional work roles (e.g., Gadassi and Gati 2009); selfobjectification among girls and women, resulting in lower self-esteem and higher depression (e.g., Fredrickson and Roberts 1997; Aubrey 2006); and acceptance of violence against women and perpetuation of the rape myth (e.g., Murnen et al. 2002; Mundorf et al. 2006). It is therefore timely to explore the link between media exposure and 
preferences and sexual attitudes among teenagers developing their attitudes and worldviews.

Media have emerged as an important socialization determinant, yet there still exists serious gaps in our knowledge of the role of media in the development of adolescent sexual attitudes and behaviors. Recently, two major reviews on the potential effects of (sexualized) media content have concluded that there is little empirical evidence on the nature and extent of media influences. Additionally, the majority of available research has addressed TV; however, other media are virtually 'terra incognita' (Escobar-Chaves et al. 2005; Ward 2003). Furthermore, investigations on the unique or combined effects of exposure to different types of media are rare and little is known of the effects of the recent rise of the internet and adolescents' consumption of explicit sexual content found using this media source. A majority of studies have focused on exposure to media, ignoring the fact that adolescents are known for their active search of media content. More attention should be given to adolescent media preferences in order to address their active roles in the selection of the media they choose to be exposed to. While it is clear, based on previous research, that adolescent girls and boys differ in their media use (e.g., Brown and Pardun 2004), in most of the reviewed studies, gender issues were understudied and accounts of gender differences in media's effects are rare. A group of researchers associated with Brown et al. (2006), L'Engle et al. (2006), and Pardun et al. (2005) have attempted to examine media comprehensively by including a wider array of media choices in their studies. Additionally, Peter and Valkenburg (2006b, 2007, 2008a, b, 2009) have incorporated exposure to explicit internet material in their research paradigms. However, to these writers' knowledge, no study has yet addressed $\mathrm{TV}$, pop music, music videos, and different types of internet use in relation to sexual attitudes.

The present study extends the literature on sexual attitudes with an investigation that models both Dutch adolescents' media exposure to and preferences for three important types of youth media. These include a wide range of TV formats, various types of pop music, music television, internet surfing and internet chatting, examined in relation to four types of sexual attitudes and stereotypes (SAS). Ward's (2002) conceptualization of sexual attitudes and stereotypes was adopted, focusing on (1) permissive sexual attitudes, (2) stereotypes of men as being primarily sex-driven, and (3) stereotypes of women as (sexual) objects. A newly developed measurement on (4) the importance of appearance for men was also included. The aim of this study was to investigate whether different types of adolescent media exposure and preferences were linked to SAS and which media factors most strongly indicated SAS. Previous research has provided strong evidence that adolescent girls and boys differ in their media preferences and sexual attitudes; therefore, in the current analyses on the links between media and sexual attitudes, gender was considered a confounding factor. Connections between media and SAS may also differ for girls and boys; therefore, gender was investigated subsequently as a potential moderator of these associations.

\section{Media as Role Models: Theory}

Schema theory (Bem 1981) posits that, during adolescence, the understanding of socially dominant definitions of male and female roles, or gender role schemas is extended and refined. The physical maturing of the body and mind and the socio-cultural context defines how to evaluate and handle these changes and prompts adolescents to develop their social and sexual selves in ways that are congruent with socially prevailing gender roles. As previously noted, parents generally follow socially defined patterns concerning these roles and tend to socialize their children accordingly; however, in terms of modeling and instructing on romance and sex, parents may fall short. Adolescents not only turn to their peers but also to media that provide ample examples of such situations (Sutton et al. 2002).

With regard to media's hypothesized effects, the current research is based on a combination of key assumptions from Priming Theory, Social Cognitive Theory, and the Media Practice Model. A central assumption of Priming Theory (Jo and Berkowitz 1994) is that stimuli can activate cognitive schemas, and that repeated activation leads to strengthening of these schema's and their rapid availability. Hence, stereotypical media portrayal of sexual roles can enhance the development and activation of schemas with similar stereotypical features. Social Cognitive Theory (Bandura 1986) postulates that people tend to learn from and imitate other people. This process is not limited to reproducing real life people's lifestyle and preferences, but extends to media models as well. Social learning is far more probable when (1) attitudes and behaviors displayed by models are relevant, (2) role models are attractive and have a high status, and (3) role models appear to benefit from displaying these attitudes and behaviors. Based on these assumptions, it can be argued that adolescents, sensitive to clues on how to refine romantic and sexual gender role schemas, generally find good-looking, socially competent, and successful media personae attractive role models (e.g., Ward et al. 2005).

Communication scientists have stressed that media exposure affects consumers, but that viewers or listeners are not passive victims, intimidated by media messages. A key notion within the Media Practice Model (MPM) (Steele and Brown 1995) is that media choices reflect the needs and preferences of consumers and that the consumers actively shape their own media environment. Currently, it is almost a truism in virtually all media research that users are anything but passive spectators and individual characteristics of consumers affect media's influence. In the present study the active involvement 
of adolescents with media was taken into account. Assuming that individual media preferences drive media use, these researchers assumed that media preferences play an important role in addition to more conventional measures of exposure to different media.

An additional condition for adolescent learning from exposure and imitation of media models is that there is at least some degree of similarity concerning the attitudes and behaviors displayed by role models. If a narrow and welldefined range of attitudes and sexual gender roles are on display, imitation seems more likely. When it comes to youth media's portrayal of romance and sex, this condition is met, as indicated by content analyses, which have provided ample evidence that stereotypical gendered representations of romance and sex prevail (Ward 2003). Hence, exposure to formulaic content of youth media may shape sexual attitudes and stereotypes, and promote chronic adoption of these schemas.

\section{Sexualized Content in Youth Media}

Reviews of content analyses of U.S. youth related media have indicated that youth media treatment of the 'sex theme' reveals large disparities in approach and influence. Some content may represent sex as a positive life-force and stress the importance of mutual respect and sexual health, while others just focus on sex's amusement value and arousing potential (Lowry and Shilder 1993; Sapolsky and Tabarlet 1991). Nevertheless, the results of these analyses also suggest that youth media's portrayal of romance and sex as joyful and loving, and malefemale relationships as equal, may be overshadowed by more frequent depictions of casual, even exploitative, and stereotypical sexual behaviors and relationships (Christenson et al. 2004; Ward 2003). Sexual health is rarely touched upon and the potential negative consequences of having sex (i.e., teenage pregnancy, STD) are systematically obscured (Hust et al. 2008).

L'Engle et al. (2006) analyzed 264 U.S. television shows, movies, music videos, and magazines, and classified approximately 28,000 units, out of a total of $236,000(12 \%)$, as having sexual content. Other content analyses of U.S. youth media in general (Kunkel et al. 2003), and more specifically, soap operas (Greenberg and Busselle 1996) and popular music songs (Dukes et al. 2003) have shown that these formats contain large amounts of sexual references and, overall, stereotypical portrayals of male and female gender roles. Other researchers have demonstrated that music videos contain high amounts of sexually charged images and mainstream and non-mainstream pop music features sexually suggestive, if not openly provocative lyrics (Arnett 2002; Baxter et al. 1985; Sherman and Dominick 1986; Ward et al. 2005). Researchers analyzing trends in U.S. pop music lyrics suggest that references to sex have become far more explicit over recent decades (Christenson et al. 2004; Dukes et al. 2003).

In particular, two music genres stand out. During the 80s and 90 s, some forms of U.S. heavy metal and hip-hop music were seen as notorious proponents of premarital sex, violence, and adolescent alcohol and drug use. Researchers found a disproportionate amount of music videos in these genres characterized by their highly stereotypical portrayal of females as sexual objects (Ter Bogt 2007). Both Arnett (1996) and Weinstein (2000) determined that, in the symbolic universe of heavy metal, two dominant roles of women are present, that of sexy seductresses and that of threatening and devouring women. Additionally, there has been an overrepresentation of leather, lingerie and latex clad, large-breasted females in song lyrics, album covers, and music videos. Content analyses of hip-hop music has revealed that hip-hop songs and music videos also contain frequent references to alcohol and drugs (Herd 2005), men portrayed as cool, tough, and potentially violent, and women depicted as play-toys and routinely referred to as 'bitches' and 'ho's'(Martino et al. 2006).

Highly explicit sexual content on the internet, the first truly worldwide medium, is easily within reach for not only U.S. adolescents but for all adolescents in countries with an internet infrastructure and home computers (Braun-Courville and Rojas 2009; Lo and Wei 2005; Peter and Valkenburg 2006a). It is therefore fair to conclude that the most important (U.S.) youth media-TV, music, music video, internet - are saturated with sounds and images of a sexually explicit nature (Brown et al. 2006; Kunkel et al. 2003; Peter and Valkenburg 2006a; Ward 2002, 2003; Ward and Friedman 2006). When frequently exposed to these media, or when actively seeking for this type of content, both girls and boys may receive confirmation that permissive sex is the norm, that looks and sexiness count for women, and that men are sex-driven creatures whose cool and tough looks enhance their pick-up skills (Ward 2002; Ward and Friedman 2006).

\section{Youth Media in the Netherlands}

In the Netherlands, a country with 16.5 million inhabitants, three national non-commercial and 11 commercial stations cater to the tastes of general audiences, by either programming a wide range of formats, or by focusing on themes such as sports, travel, comedy, adventure, or documentaries. In addition, two day-time stations address children and early adolescents and two other stations target teens and young adults (Sikkema 2007). Three of the four stations catering to youth belong to the MTV Benelux group and present a mix of music videos, cartoons, and other programs tailored to children's, adolescents', and young adults' preferences. In particular, commercial stations depend heavily on foreign (i. e., American) content and a significant proportion of Dutch TV is, in fact, American TV. Not only is TV 'Americanized,' 
the same holds for pop music. Since the fifties, American pop music has been important, if not dominant, in the Dutch music charts. Large, often American, media corporations acting globally, have left their footprint on the Dutch media landscape (Ter Bogt 2000).

Approximately half of the Netherlands adolescents in the 15-19 year age group report daily TV viewing of $2 \mathrm{hr}$ or more. Radio and music listening through personal audio is similar in terms of amount of time listening to these media. The greatest shift in Dutch adolescent media consumption relates to the advent of the internet. The Netherlands ranks among the countries with the highest penetration of broadband internet. While radio listening and reading magazines has decreased, now more than $95 \%$ of Dutch adolescents report using computers to find information, chat, surf, or listen and download music (Sikkema 2007). For example, 13-17-yearolds spent, on average, 1.5-2 hr per day in front of their computer screens (SPOTtime 2008). In recent Dutch surveys, findings indicate that a substantial proportion of Dutch youth consume adult internet content (Hawk et al. 2006). Peter and Valkenburg (2006a) observed that during a 6-month period preceding their survey, approximately $75 \%$ of $13-18$-year-old males, and $40 \%$ of females had at least once been exposed to on-line graphic sexual content.

Each day, for a considerable period, Dutch youth consume American, or similar, media formats. Detailed content analyses of the degree of sexualized typecasting in Dutch youth media currently do not exist; however, in a large 24-country study including the Netherlands, of gender representation in youth $\mathrm{TV}$, high cross-national similarities were found in stereotyped representations of women and men (Götz et al. 2008). Based on this information, it is fair to propose that Dutch youth are subject to similar stereotypical messages as their peers in the U.S., or, for that matter, young people in other countries with a high proportion of youth media content of American origin. However, it must be noted that that cross-cultural differences in the interpretation of these messages are possible. In the Dutch context, these stereotypical messages may be less relevant or meaningful, as the wider socio-cultural context advocates little gender differentiation (e.g. Hofstede 2001). Regardless, even in this context, youth media can be conceptualized as a main factor pushing the other way (i.e., promoting stereotypical gender roles and sexual attitudes).

\section{Media, Gender, Sexual Attitudes and Stereotypes}

It is remarkable that teen media use, at least in the U.S., the UK, and the Netherlands, often has a solitary nature: most young people watch, listen, game, surf, and chat in the relative privacy of their own room, that is, free from parental monitoring or comments (North et al. 2000; Sikkema 2007; Ward 2002). In turn, unmonitored consumption of media results in more exposure to sexual content within that media (Kim et al.
2006). Cross-sectional and longitudinal investigations have found that frequent exposure to sexual media content is associated with intentions to have sex and accelerated adolescents' initiation and continuation of sexual activities (Aubrey et al. 2003; Brown et al. 2005; Collins et al. 2004; Kim et al. 2006; L'Engle et al. 2006; Martino et al. 2006; Martino et al. 2005).

Media may not only affect behaviors, but may also be of prime importance for adolescents' general ideas of romance, sex, and relationships. In the U.S., exposure to youth TV content or prime-time TV (i.e., soaps operas, drama, talkshows) has been linked to more positive attitudes toward casual, pre-, or extramarital sex (Bryant and Rockwell 1994; Huston et al. 1998; Ward and Rivadeneyra 1999; Ward 2002; Ward and Friedman 2006). Similarly, exposure to music television has been connected to permissive attitudes in the U.S. (Calfin et al. 1993; Greeson and Williams 1986; Strouse et al. 1995; Ward and Frieman 2006; Ward et al. 2005). The link between consumption of sexually explicit internet material and endorsement of casual sex has also been confirmed in research conducted in Hong Kong (Lam and Chan 2007), the Netherlands (Peter and Valkenburg 2006b, 2008b), Taiwan (Lo and Wei 2005), and the U.S. (Carroll et al. 2008; Braun-Courville and Rojas 2009).

In the U.S. context, exposure to prime time TV or youth TV content, has also been associated with more stereotypical sexual attitudes and evaluation styles (i.e., the view that men are stereotypically sex-driven, the notion of women are sexual objects to be valued for their looks) (Ward 2002; Ward and Friedman 2006; Zurbriggen and Morgan 2006), and, more generally, the idea that appearance or sexiness is of key importance for both women (e.g., Aubrey 2006) and men (e.g., Smolak and Stein 2006). Pop music and music videos have also been shown to amplify stereotypical gender schemas (Arnett 2002; Carpentier et al. 2007; Hansen and Hansen 1988; Hansen and Krygowski 1994; Ward et al. 2005), to foster beliefs that gender relationships are adversarial (Kalof 1999), and that appearance is allimportant (Borzekowski et al. 2000; Ward et al. 2006). Recently, the negative effects of exposure to sexually explicit internet material have become more certifiable. In a Dutch study, researchers found that watching pornographic content was significantly associated with sexual objectification of women (Peter and Valkenburg 2007). Of further note, studies on the effects of sexually explicit internet material have shown that, relative to other media content, exposure to and preference for the most sexually explicit material, is indicative of the strongest endorsement of permissive sex and sexual stereotyping (Lo and Wei 2005; Peter and Valkenburg 2006b, 2007).

In most of the studies reviewed here, gender differences have not been explicitly tested. However, from the studies that did explicitly examine this content, it is clear that, across 
countries, boys and young men tend to search for sexy content more often than girls and women (Peter and Valkenburg 2008a, b; Wolak et al. 2007); however, with regard to the links between sexualized media content, sexual attitudes, and stereotypes, mixed results emerged. For example, Ward (2002), and Strouse et al. (1995) reported that, in relation to media use, young women were more sensitive to notions of the importance of appearance and sexiness and more inclined to endorse permissive ideas than boys were. Conversely, Aubrey (2006) and Peter and Valkenburg (2007) did not find gender differences in connection with youth media exposure and permissive attitudes and sexual stereotypes. It must be noted that results of these studies are difficult to compare as they concern diverse media formats and different measurements of attitudes and stereotypes.

\section{The Present Study}

Research on multi-media exposure and use and sexual attitudes and stereotypical gender-role schemas (SAS) is scarce (Escobar-Chaves et al. 2005; Ward 2003). As far as the authors of the present study know, exposure to and preferences for the three most consumed adolescent media in the Netherlands, TV, music/music video, and the internet, have not been included in one systematic approach.

In the present study, the active involvement of adolescents with media was taken into account by modeling preferences, in addition to more conventional measures of exposure. A wide range of TV (nine) and music preferences (ten) was included in the current study. In addition, respondents' propensity to use the internet in different ways was measured. Preference for four types of surfing and three types of communicating with peers were integrated into the research designs.

Research has demonstrated that media choices and sexual attitudes and stereotypes co-vary with personality factors such as sensation seeking, sexual experience, and background characteristics such as educational attainment (reviews Eggermont 2006; Hawk et al. 2006; Peter and Valkenburg 2007). In order to provide a balanced account of the extent to which media exposure and preferences (MEP) relate to SAS, education, sensation seeking, and sexual experience were included in the analyses as confounding factors. Furthermore, gender is an important factor related to this topic. As adolescent females and males differ in their media viewing and both groups manifest sexual attitudes and stereotypes to different degrees (e.g., Ward 2003), gender was introduced as a confounder of the relation between those two sets of factors. Next, in order to explore whether media were similarly associated with SAS for boys and girls, it was relevant to subsequently test whether gender moderated the links between MEP and SAS.

Finally, much research has been directed toward college students (in the U.S.) and investigations among teenagers from 12 to 16-years-old, the group most intensely involved in developing sexual attitudes, is limited (Peter and Valkenburg 2007; Ward and Friedman 2006; Ward et al. 2005). The current research is one of the few conducted outside the U.S., which addresses this highly important group of early and mid-adolescents at the early stages of their sexual identity formation.

Figure 1 shows a simplified model of media exposure and preferences (MEP) and sexual attitudes and stereotypes (SAS). On the left side of Fig. 1, personal characteristics are represented (gender, educational level, sexual experience, and sensation seeking). Also included are media exposure (TV, music/music TV, internet surfing, internet chatting); music preferences (10 genres); and internet preferences (four types of surfing and three types of chatting). On the right side, indicated by ellipses, four latent factors are shown, representing sexual attitudes (casual sex is $\mathrm{OK}$ ) and stereotypes (men are sex-driven, women as objects, men as tough). Single headed arrows indicate possible links between background characteristics, personality, and MEP, on the one hand, and SAS on the other. The double headed arrows indicate potential covariation between predictors and between outcomes. Therefore, the current study extends the prior literature by exploring the relative importance of different types of media for the endorsement of sexual attitudes and stereotypical gender-role schemas, while controlling for confounders that have been shown to influence sexual attitudes. Additional multigroup analyses explore potential gender differences in these links.

This study attempted to answer three questions;

RQ 1: Are different types of media exposure and preferences linked to adolescent sexual attitudes and gender stereotypes?

RQ 2: Which media factors most strongly indicate sexual attitudes and gender stereotypes?

RQ 3: Are relations between media exposure and preferences and sexual attitudes and gender stereotypes moderated by gender?

Based on the review of the literature, it is difficult to formulate precise hypotheses, as prior research addressed many different media formats and content types, mostly separately. In addition, associations between MEP and SAS may, or may not be gender specific. Three general hypotheses can be formulated. As youth media generally contains frequent references to sex and stereotypical portrayals of gender-roles it was expected that:

H1: More frequent exposure to youth media-TV, music/ music videos, internet - is correlated with higher endorsement of permissive sex and more stereotypical gender-role attitudes. 
Fig. 1 Structural model of personal characteristics, media use, and sexual attitudes and stereotypes.
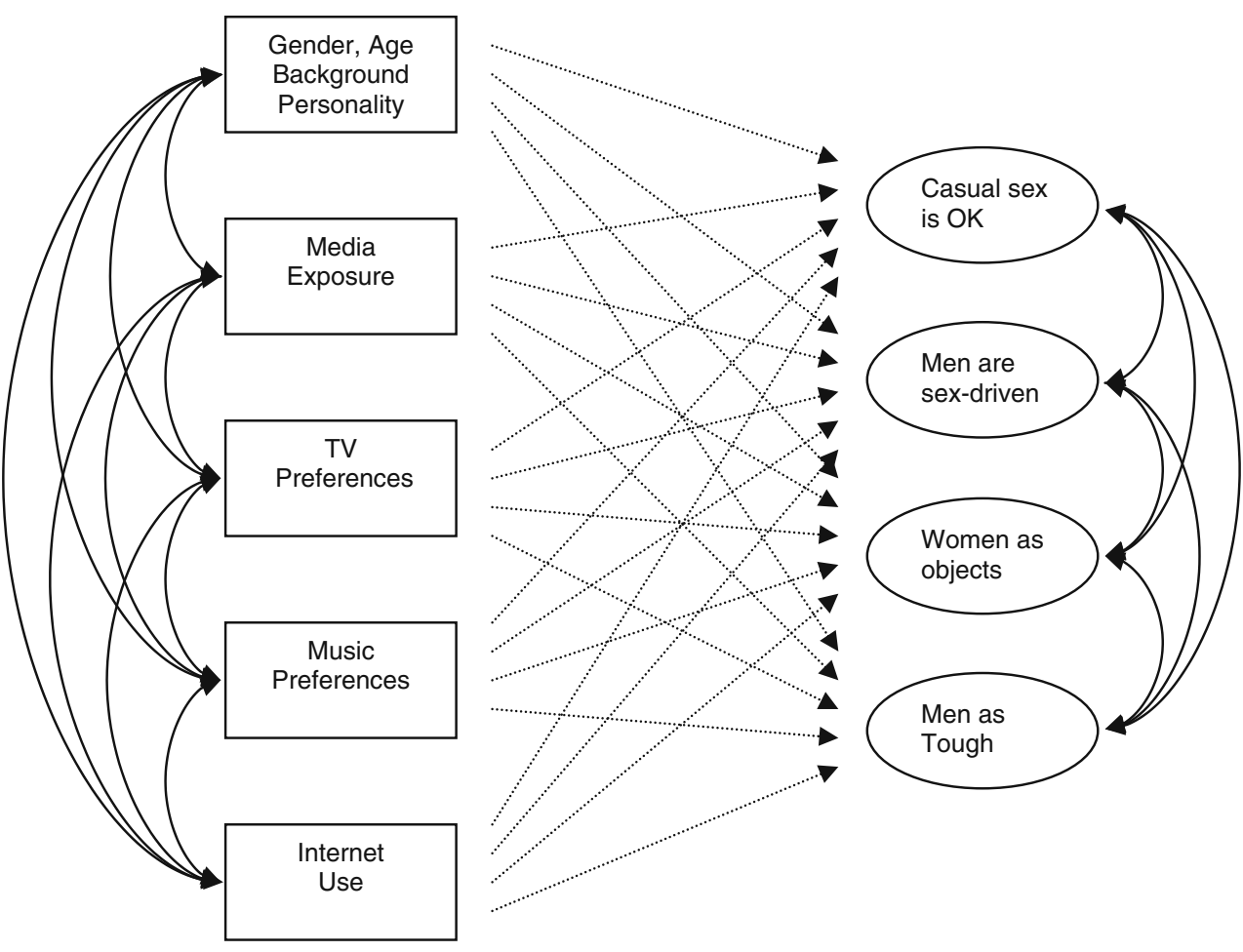

Some genres stand out for their typecasting, in particular, music videos, and hip hop and heavy metal music. Preferring the most stereotypical media may be connected more strongly with permissiveness and stereotypical attitudes:

H2: Preferences for specific media types - music videos, heavy metal and hip-hop music-are linked to stronger endorsement of permissive sex and stereotypical gender-role attitudes, when other factors are controlled.

Exposure to and preferences for the most sexually explicit content has been related more strongly to permissive attitudes and sexual stereotypes compared to weaker content. It was therefore expected that:

H3: Preferences for sexually explicit TV or internet content is the strongest indicator of permissive sex and stereotypical gender-role attitudes when other factors are controlled.

\section{Method}

Sample and Procedure

Participants included 496 second and third-grade adolescents (47\% female, $53 \%$ male) from three schools across the Netherlands. The age of the respondents ranged from 13 to 16-years-old $(M=14,3$ years, $S D=.84)$. Education was defined as the current school level of the adolescents. The secondary school system in the Netherlands is divided into two branches. In the current sample, education level was equally distributed ( $48 \% \mathrm{VMBO}$, or lower level vocational education; $52 \% \mathrm{HAVO} / \mathrm{VWO}$, or higher level education). Seventy-seven percent of respondents were Dutch, $16 \%$ were from non-western countries, mainly Turkey and Morocco, and former Dutch colonies: Surinam and the Dutch Antilles. Additionally, $7 \%$ of respondents were immigrants from western (EU) countries. Sixteen respondents were removed from the analysis because of missing data on the outcome variables, resulting in a sample of 480 adolescents with complete data.

Parents of the students were notified prior to the beginning of the study by means of a personal letter which requested permission to include their child in a study on media use, personality factors, and attitudes toward sexuality and romance. The authors explained that the data would be treated as strictly confidential. Parents indicated whether they did not want their children to participate (passive informed consent). Participants freely choose to participate and confidentiality was ensured at all stages of the study. In the data files no link was made to the names of respondents. For the study of sensitive issues, computer-mediated surveys have generally proven superior to other modes of interviewing (Mustanski 2001). All participants completed an on-line questionnaire in the media-lab of their schools. The space between each computer was enough to guarantee privacy and prevent 
carry-over effects between participants. Survey completion took $30-45 \mathrm{~min}$.

\section{Measures}

\section{Sexual Attitudes}

A translated and simplified version of the Attitudes Toward Dating and Relationships (Ward 2002) was used to assess participants' sexual attitudes and stereotypes. The original questionnaire contained 19 items and consisted of three subscales: 'Dating is a game or recreational sport,' 'Men are Sex-driven,' and 'Women as Sexual Objects.' These scales were designed for questioning American college students. These researcher adapted the content to use among the younger, and on average, less educated group in the current study. 'Dating' as a ritualized form of starting a romance is uncommon in the Netherlands; therefore, items directly relating to dating concerns were omitted. Furthermore, compared to the older group of U.S. respondents in Ward's study, adolescents were less experienced in maintaining relationships and balancing power while doing so. Therefore, these researchers refrained from using the items on power management within relationships. Finally, when translating, these researchers attempted to come up with a simpler type of language that was comprehensible for our younger sample of adolescents and relevant to their stage of development (details on scale construction can be obtained from the first author).

Ward's 'Dating is a game or recreational sport' scale items were adjusted and the scale was refocused on sexual permissiveness. To the two original items, a third was added and was renamed 'Casual Sex is OK.' Items included: "You don't need a relationship to have good sex; all you need are two people who are attracted to each other;" "Sexual activity is desirable as early in a relationship as possible;" "It's OK to have sex with several different people, because then you start getting good at it." Reliability as calculated: $\alpha=.66$.

From the second sexual attitudes scale, 'Men are Sexdriven,' three central and easy to grasp items were retained and translated into Dutch: "Boys are always ready and willing for sex; they think about it all the time;" "Boys ogle girls, even if they have a girlfriend;" "Boys more often think of sex and therefore they cannot be faithful to their girlfriends." Reliability: $\alpha=.66$.

From the third subscale 'Women as Sexual Objects,' four items were translated and put into more simple wording: "A beautiful girl attracts comments on her appearance and should be able to handle that;" "Girls should really take care of their appearance, boys don't want an ugly girl as a girlfriend;" "A girl has to look sexy in order to be attractive to boys;" "It is cool for a guy to have a sexy girlfriend." Reliability: $\alpha=.71$.

The significance of looks has been the subject of much investigation in the sexual attitudes literature; however, the importance of boys' appearance has attracted less attention. Therefore, a fourth scale was added, assessing stereotypical attitudes on the importance of being handsome and well-built: 'Men as Tough;' "Handsome boys can get any girl," "It is cool for a girl to have a real hunk as a boyfriend;" "Girls prefer a tough guy as a boyfriend;" "As a boy, you better be a macho then a nerd." Reliability was calculated $\alpha=.64$. All four attitude scales adopted the same response categories as Ward used: 1 (strongly disagree), 2 (disagree), 3 (slightly disagree), 4 (slightly agree), 5 (agree) and 6 (strongly agree).

To test the structure of the SAS scales, these researchers conducted a Confirmatory Factor Analysis (AMOS 7) (Arbuckle 2006). Factors were allowed to correlate but the errors of items indicating the four different SAS factors were not allowed to correlate. The results indicated a clear four factor structure with all factor loadings $>.45$ and no hints of significance cross the factor loading of items $\left(X^{2}=\right.$ 190.6, $\mathrm{df}=71, \mathrm{CFI}=.925$, RMSEA $=.059$ ). Second, in a multiple group test, these researchers analyzed whether the factor structure differed for boys and girls. In order to do so, factor loadings were freely estimated and subsequently the loadings were set to be constrained across groups. The fit indices for the constrained multi-group model were $\mathrm{X}^{2}=$ 290.0, $\mathrm{df}=152, \mathrm{CFI}=.910, \mathrm{RMSEA}=.044$ ), indicating good fit. The model comparison test indicated that constraining the scale items across groups resulted in a significantly better model than the freely estimated model $(\triangle \mathrm{CMIN} 19.2$, $p<.05)$ (Hu and Bentler 1999). These researchers conclude that an exact identical structure with identical factor loading emerged for boys and girls, indicating solid cross gender validity of these scales.

\section{Media Exposure}

Four items on the frequency of daily exposure to media were included: "How much time do you spend on the following media on a daily basis," TV, music/music TV, internet surfing, and internet chatting were included as response categories: 1 (none), 2 (less than $1 \mathrm{hr}$ ), 3 (1-2 hr) $4(2-3 \mathrm{hr}$ ), and 5 (more than $3 \mathrm{hr}$ ).

\section{TV Preferences}

Nine items on the preference for different types of TV content were included: "How much do you like the following TV programs:" news/info, comedies, soaps, reality TV, romantic movies, thrillers/action movies, sports, music TV, and erotica. Participants rated their responses on a 5-point Likert scale with response categories 1 (dislike 
very much), 2 (dislike), 3 (do not dislike or like), 4 (like), and 5 (like very much).

\section{Music Preferences}

The music preference questionnaire (Sikkema 2005) included ten items on liking the most prevalent genres within music. "How much do you like the following types of music:" chart music, hip hop, R\&B, rock, heavy metal, punk/alternative, dance/house, techno, hard-house, and classic music. Participants rated their responses on a 5point Likert scale with response categories 1 (dislike very much), 2 (dislike), 3 (do not dislike or like), 4 (like), and 5 (like very much).

\section{Internet Surfing}

Respondents were asked if they ever surfed on the internet. "Do you use the internet for the following purposes:" for fun, to find information, to listen to or download music, and to view erotic content. Four items rated on a 5-point Likert scale included the response categories 1 (never), 2 (less than once a month), 3 (1 to 3 times a month), 4 (weekly), and 5 (daily).

\section{Internet Chatting}

Respondents were asked if they ever used chat programs or messaging services for three different purposes. "Do you use chat or messaging services for:" chatting with friends, finding new friends, and finding a romantic partner. Three items were rated on a 5-point Likert scale with response categories 1 (never), 2 (less than once a month), 3 ( 1 to 3 times a month), 4 (weekly), and 5 (daily).

\section{Sexual Experience}

Using five NISSO items (De Graaf et al. 2005), respondents were asked about their sexual experiences. "Have you ever experienced:" sexual arousal, fantasizing about sex, masturbation, kissing, petting, and intercourse. Answering categories included 1 (none), 2 (some), and 3 (much). The sexual experience scale was constructed by summarizing the item scores; $\alpha=.83$.

\section{Sensation Seeking}

Five items addressing thrill seeking from the Brief Sensation Seeking Scale were included (Hoyle et al. 2002). Sample questions include: "I would like to try bungee jumping;" "I would love to have new and exciting experiences, even if they are illegal;" "I prefer friends who are excitingly unpredictable;" "I like wild parties;" and "I get restless when I spend too much time at home." Response categories included: 1 (strongly disagree), 2 (disagree), 3 (neither disagree nor agree), 4 (agree), and 5 (strongly agree); $\alpha=.74$

\section{Strategy of Analysis}

First, these researchers examined group differences including gender, age, education, and ethnicity in regard to attitudes and stereotypes (MANOVA). Second, in order to determine links between media consumption and preferences and SAS (RQ 1), zero-order Pearson correlations were computed between the media factors and SAS. Third, media variables were modeled as predictors of SAS while controlling for confounders (see Fig. 1). To test which factors most clearly indicated SAS (RQ 2), variables that revealed significant Pearson correlations with SAS were introduced in the SEM model, but retained only if they were significantly connected and uniquely explained variance of the SAS outcomes. This procedure aided in identifying the strongest media markers of SAS, while controlling for personality and background factors. The errors of items loading on the four different SAS factors were not allowed to correlate nor were any other error terms. Fourth, the structural model was tested for differences between boys and girls in a multi-group set-up. Indicators for latent SAS constructs were constrained across groups, paths from media factors to SAS were also constrained to be equal across the two groups, and these paths were released subsequently. A significant increase in model fit was used as a criterion for distinguishing separate girls' and boys' paths in these models.

\section{Results}

Descriptive Results

Table 1 shows the descriptive findings on boys' and girls' media exposure and media preferences. In this group of secondary school students, the internet was the most important medium in terms of daily use. Approximately half of the adolescents reported surfing and chatting for more than $2 \mathrm{hr}$ daily. Television was also popular and long exposure to music videos (that are not so much watched, but play in the background) was confined to a relatively small group of about $10 \%$ or fewer. Comedy, movies, and music videos were the most popular TV genres. Girls tended to prefer soap operas, romantic movies, and music videos more than boys did; the opposite held for preferences for news/ info, action movies, and erotica $(p<.01)$. The most popular types of music were chart music, Black American music (hip-hop, R\&B), and dance music (dance/house and hardhouse). Girls reported preferring chart music and R\&B; whereas, boys indicated more fondness for rock music 
Table 1 Gender, media exposure and media preferences.

\begin{tabular}{|c|c|c|c|}
\hline & Boys & Girls & Total \\
\hline \multicolumn{4}{|c|}{ Exposure $(\%>2$ hrs per day) } \\
\hline TV & 44.9 & 42.2 & 43.6 \\
\hline Music videos & 6.3 & 10.6 & 8.4 \\
\hline Internet surfing & 47.6 & 47.6 & 47.5 \\
\hline Internet chatting & 27.2 & 37.7 & 32.1 \\
\hline \multicolumn{4}{|c|}{ TV preferences (scale 1-5) } \\
\hline News/info & $2.9(.9)$ & $2.7(.9)$ & $2.8(.9)$ \\
\hline Comedy & $4.3(1.0)$ & $4.3(.9)$ & $4.3(.9)$ \\
\hline Soap & $2.6(1.2)$ & $4.0(1.1)$ & $3.3(1.3)$ \\
\hline Reality TV & $2.7(1.2)$ & $3.0(1.1)$ & $2.8(1.2)$ \\
\hline Romantic movies & $2.8(1.2)$ & $4.2(.9)$ & $3.5(1.3)$ \\
\hline Action movies & $4.6(.8)$ & $4.3(.9)$ & $4.5(.8)$ \\
\hline Sports & $4.0(1.3)$ & $2.8(1.4)$ & $3.4(1.4)$ \\
\hline Music Videos & $4.0(1.1)$ & $4.2(.9)$ & $4.0(1.0)$ \\
\hline Erotica & $3.5(1.2)$ & $2.1(1.0)$ & $2.7(1.3)$ \\
\hline \multicolumn{4}{|c|}{ Music preferences (scale 1-5) } \\
\hline Chart pop & $3.7(1.1)$ & $4.1(1.0)$ & $3.9(1.1)$ \\
\hline Hip-hop & $3.6(1.4)$ & $3.9(1.2)$ & $3.7(1.3)$ \\
\hline $\mathrm{R} \& \mathrm{~B}$ & $3.5(1.4)$ & $4.0(1.2)$ & $3.7(1.3)$ \\
\hline Rock & $2.9(1.4)$ & $2.6(1.3)$ & $2.8(1.4)$ \\
\hline Heavy Metal & $2.1(1.3)$ & $1.8(1.1)$ & $2.0(1.2)$ \\
\hline Punk/Alternative & $2.6(1.6)$ & $2.5(1.5)$ & $2.5(1.5)$ \\
\hline Dance/House & $3.3(1.3)$ & $3.4(1.1)$ & $3.4(1.2)$ \\
\hline Techno & $2.7(1.4)$ & $2.5(1.3)$ & $2.6(1.2)$ \\
\hline Hardhouse & $3.5(! .5)$ & $3.4(1.4)$ & $3.4(1.5)$ \\
\hline Classic music & $1.7(1.0)$ & $1.7(.9)$ & $1.7(1.0)$ \\
\hline \multicolumn{4}{|c|}{ Internet surfing (scale 1-5) } \\
\hline Fun & $4.0(.9)$ & $3.8(.9)$ & $3.9(.9)$ \\
\hline Info & $2.9(1.1)$ & $2.9(1.0)$ & $2.9(1.0)$ \\
\hline Music & $4.3(.9)$ & $4.5(.7)$ & $4.4(.8)$ \\
\hline Erotica & $3.3(1.3)$ & $1.6(.9)$ & $2.5(1.4)$ \\
\hline \multicolumn{4}{|c|}{ Internet chatting (scale 1-5) } \\
\hline Friends & $4.4(.9)$ & $4.5(.9)$ & $4.4(.9)$ \\
\hline New friends & $3.2(1.2)$ & $3.0(1.2)$ & $3.1(1.2)$ \\
\hline Romantic partners & $2.8(1.2)$ & $2.4(1.2)$ & $2.6(1.2)$ \\
\hline
\end{tabular}

Scales range from 1 "do not like at all/never" to 5 "like very much/ daily". Bold typeface indicates gender differences (t-tests, $p<.01$ ).

$(p<.01)$. The internet was primarily used for fun surfing and listening to and downloading music. A significant difference between boys and girls occurred in regard to preference for internet erotica, which was far more popular among boys than girls $(p<.01)$.

Table 2 depicts adolescents' background to their endorsement of sexual attitudes and stereotypes. A 2 (gender)* 2 (age) $* 2$ (ethnicity) $* 2$ (education) $* 4$ (SAS) MANOVA revealed multivariate differences for gender (Wilks' $F(4,466)=20.92, p<.001$ ) and education (Wilks' $F$
$(4,466)=6.13, p<.001)$. No significant differences were found between age group and ethnic background. Between-subjects test effects revealed that, on average, boys were more inclined to respond positively to the idea that casual sex is $\mathrm{OK}$ and that sexiness is important for women and higher educated adolescents more often believed in the positive value of permissive sex $(p<.05)$. Furthermore, a few significant interaction effects were found (not in table). Compared to their more educated peers, less educated boys did not think that men are sexdriven. Fewer more educated girls believed that males should be tough and handsome and this group was also less inclined to believe that looks are all-important for women $(p<.05)$.

Are Media Exposure and Preferences Correlated to Sexual Attitudes and Gender Stereotypes?

Table 3 depicts the Pearson correlations between media factors and SAS. Exposure was linked to SAS. For girls, but not boys, exposure in the form of heavy TV viewing and internet surfing and chatting, was generally related to higher SAS scores. TV preferences were also linked to SAS. For girls, preferring news/info was linked negatively to SAS, while preferring soap operas was associated positively with all three gender stereotypes. For all adolescents, the preference for romantic movies and music videos generally indicated higher SAS scores. Liking sports was connected positively to stereotypes for boys, but not girls, and these relationships were significantly different. For boys a positive relationship between viewing TV erotica, and attitudes and stereotypes was found and these associations were significantly stronger for boys than for girls.

Music preferences were also correlated to attitudes and stereotypes (see Table 3). For both boys and girls, preferring hip-hop, R\&B, and hard-house music pointed to stronger endorsement of attitudes and stereotypes. Particularly, for girls, preferences for classical music, rock, and heavy metal indicated less agreement with stereotypes. For girls liking punk, results indicated a positive association with endorsing permissive sexual attitudes, while for boys liking this type of music, results indicated more stereotyping.

For girls, internet surfing for fun and using the internet to find information was negatively correlated to sexual attitudes and stereotypes (see Table 3). For boys, using the internet to surf for erotica was a strong indicator of higher SAS scores and three of these relationships were stronger for boys compared to girls. For boys, using the internet search for romance was also a significant indicator of SAS.

Partial support was found for the first hypothesis, more frequent exposure to youth media-TV, music/music video, internet - is related to higher endorsement of permissive sex 
Table 2 Estimated marginal means and standard errors of sexual attitudes and stereotypes by background characteristics.

SAS scale scores ranging from $1-5$, values in parentheses represent standard errors. Means with different superscripts refer to univariate between group differences at $p<.05$ in a 2 (Gender) $* 2$ (Age) $* 2$ (Ethnicity) $* 2$ (Education) $* 4$ (SAS) MANOVA $(p<.05)$

\begin{tabular}{|c|c|c|c|c|c|c|c|c|}
\hline & \multicolumn{2}{|c|}{ Casual sex OK } & \multicolumn{2}{|c|}{ Men sex-driven } & \multicolumn{2}{|c|}{ Women as objects } & \multicolumn{2}{|c|}{ Men as tough } \\
\hline \multicolumn{9}{|l|}{ Gender $(\mathrm{N})$} \\
\hline Boys (254) & $2.43^{\mathrm{a}}$ & $(.085)$ & 3.58 & $(.093)$ & $3.63^{\mathrm{a}}$ & $(.092)$ & 3.73 & $(.087)$ \\
\hline Girls (226) & $1.70^{\mathrm{b}}$ & $(.088)$ & 3.72 & $(.097)$ & $2.92^{\mathrm{b}}$ & $(.095)$ & 3.59 & $(.090)$ \\
\hline \multicolumn{9}{|l|}{ Age } \\
\hline $13-14(296)$ & 2.10 & $(.084)$ & 3.64 & $(.092)$ & 3.37 & $(.091)$ & 3.66 & $(.086)$ \\
\hline $15-16(184)$ & 2.03 & $(.089)$ & 3.66 & $(.098)$ & 3.17 & $(.097)$ & 3.65 & $(.092)$ \\
\hline \multicolumn{9}{|l|}{ Education } \\
\hline Low (233) & $1.87^{\mathrm{a}}$ & $(.109)$ & 3.52 & $(.120)$ & 3.33 & $(.118)$ & 3.78 & $(.112)$ \\
\hline High (247) & $2.25^{\mathrm{b}}$ & $(.072)$ & 3.78 & $(.079)$ & 3.21 & $(.078)$ & 3.54 & $(.074)$ \\
\hline \multicolumn{9}{|l|}{ Ethnicity } \\
\hline Caucasian (372) & 2.15 & $(.058)$ & 3.60 & $(.064)$ & 3.28 & $(.063)$ & 3.66 & $(.059)$ \\
\hline Ethnic minority (108) & 1.98 & $(.116)$ & 3.70 & $(.128)$ & 3.27 & $(.126)$ & 3.65 & $(.119)$ \\
\hline
\end{tabular}

and more stereotypical gender-role attitudes. For girls only, heavy exposure to $\mathrm{TV}$ and internet related to higher endorsement of casual sex, the idea that men are sex driven, and stereotyping women as objects and men as tough.

\section{Which Media Factors Most Strongly Indicate SAS?}

In addition to gender and other background characteristics, the structural SAS model first contained all media variables with significant Pearson correlations to SAS. This model was then trimmed to the essentials by removing nonsignificant paths to SAS outcomes. A significant covariation between predictors and between outcomes were also retained in the model. The resulting model showed good fit $\left(\mathrm{X}^{2}=374.96, \mathrm{df}=180, \mathrm{CFI}=.923\right.$, RMSEA=.048). First, as seen in Table 4, several connections between background characteristics and media factors were identified. Girls were less inclined to sensation seeking (path coefficient,-.25) and reported less sexual experience (-.32). Girls were more in favor of hip-hop music (.09) and surfed the internet in search for erotic content (-.59) less often than boys. Educational level was negatively linked to liking hardhouse music (-.20) and positively linked to classic music (.13). Adolescents with more education surfed the internet for erotica (.10) more often than those with less education. Sensation seeking was connected to preferring hard-house (.13) and disliking classical music (-.10) and sensation seeking and sexual experience were both related to surfing for erotic content (.32 and .57 respectively) and were interlinked (.37).

Second, associations between personal characteristics and SAS were also found. Girls tended to think less often that casual sex is OK $(-.12)$ and were less inclined to see women as objects (-.21); however, more often endorsed the idea that men are sex-driven (.28). Youth with higher levels of education were more in favor of casual sex (.15).
Sensation seeking was positively related to endorsing casual sex (.13). Sexual experience emerged as a strong indicator of SAS; experienced adolescents more often approved of these ideas than their less sexually experienced peers (all path coefficients $>.17$ ).

Third, in the trimmed model, a limited number of media variables surfaced as significantly related to SAS. Only three types of music preferences, hip-hop, hard-house, and classic music, and one type of internet use, surfing for erotica, was associated with attitudes and stereotypes when modeling SAS economically. Music preferences, in particular, related to the importance of appearance stereotypes. Preference for hip-hop (.12/.14) and hard-house music (.19/ .27) were positively associated to the belief that women were objects and men were tough; whereas, preferring classical music was negatively $(-.15 /-.14)$ associated to the above stereotypes. Surfing for erotica emerged as a strong predictor for endorsement of all four attitudes and stereotypes (all path coefficients $>.15$ ).

\section{Are Relations Between MEP and SAS Moderated by Gender?}

In the multi-group analyses with gender as a criterion $\left(\mathrm{X}^{2}=\right.$ 577.16, $\mathrm{df}=352, \mathrm{CFI}=.890, \mathrm{RMSEA}=.037$ for the fully constrained model), only one significant difference was found concerning the links between media factors and SAS. For boys (.36), preferring internet erotica was more strongly related to the idea that men are sex driven when compared to the beliefs held by girls $(.03)\left(\Delta X^{2}=9.36, p<.01\right.$, when releasing constraint). Hence, this multivariate analysis partially corroborated results of a correlational analysis in that internet use was a stronger marker of at least one type of stereotype for boys compared to girls. In the paths between music preferences and SAS, no further gender differences were found, implying that, although boys and girls varied in their media preferences and their endorse- 
Table 3 Pearson correlations between media use, and sexual attitudes and stereotypes.
Zero order correlations,

$* p<.05, * * p<.01$; bold typeface: correlations for boys and girls are significantly different at $p<.01$

\begin{tabular}{|c|c|c|c|c|c|c|c|c|}
\hline & \multicolumn{2}{|c|}{ Casual sex OK } & \multicolumn{2}{|c|}{ Men sex-driven } & \multicolumn{2}{|c|}{ Women as objects } & \multicolumn{2}{|c|}{ Men as tough } \\
\hline & Boys & Girls & Boys & Girls & Boys & Girls & Boys & Girls \\
\hline \multicolumn{9}{|l|}{ Exposure } \\
\hline TV & -.05 & $.19 * *$ & .03 & $.14^{*}$ & -.09 & .09 & .00 & $.16^{*}$ \\
\hline Music videos & $.15^{*}$ & $.15^{*}$ & .10 & .07 & .11 & .10 & .08 & .10 \\
\hline Internet surfing & .04 & $.18^{* *}$ & .03 & $.17 *$ & -.09 & $.16^{*}$ & .01 & .11 \\
\hline Internet chatting & .05 & $.25^{* *}$ & .10 & $.22 * *$ & .02 & $.19 * *$ & .00 & $.20 * *$ \\
\hline \multicolumn{9}{|l|}{ TV preferences } \\
\hline News/info & -.09 & $-.20 * *$ & .01 & $-.21 * *$ & -.08 & -.10 & -.07 & $-.16^{*}$ \\
\hline Comedy & -.03 & -.01 & -.03 & -.07 & -.06 & -.01 & -.06 & .08 \\
\hline Soap & .06 & -.05 & .10 & $.18^{* *}$ & .12 & $.20^{* *}$ & .09 & $.21 * *$ \\
\hline Reality TV & .08 & -.05 & .11 & .10 & .12 & .03 & .10 & .11 \\
\hline Romantic movies & $.16^{*}$ & .04 & $.13^{*}$ & .02 & .05 & $.17 * *$ & $.13^{*}$ & $.23 * *$ \\
\hline Action movies & .02 & .01 & .03 & .10 & .08 & .04 & .06 & .05 \\
\hline Sports & .09 & -.05 & $.13 *$ & $-.13 *$ & $.22 * *$ & -.10 & $.13^{*}$ & .01 \\
\hline Music Videos & .12 & $.23 * *$ & $.13 *$ & $.11^{*}$ & $.18^{* *}$ & $.29 * *$ & .11 & $.22 * *$ \\
\hline Erotica & $.42 * *$ & $.15^{*}$ & $.34 * *$ & .04 & $.42 * *$ & .13 & $.26^{* *}$ & .07 \\
\hline \multicolumn{9}{|l|}{ Music preferences } \\
\hline Chart pop & -.07 & -.04 & .03 & -.07 & $.12 *$ & .06 & .08 & .07 \\
\hline Hip-hop & $.14^{*}$ & .04 & $.16^{*}$ & $.15^{*}$ & $.20 * *$ & .10 & $.13^{*}$ & $.18^{* *}$ \\
\hline $\mathrm{R} \& \mathrm{~B}$ & .12 & .04 & $.16^{* *}$ & .13 & $.15^{*}$ & $.15^{*}$ & $.13^{*}$ & $.21 * *$ \\
\hline Rock & .00 & .07 & -.04 & -.05 & -.01 & -.08 & -.09 & $-.13 *$ \\
\hline Heavy Metal & .00 & .11 & -.02 & -.03 & -.03 & -.11 & -.08 & $-.14 *$ \\
\hline Punk/Alternative & .11 & $.15^{*}$ & .10 & -.02 & $.14 *$ & .10 & $.15^{*}$ & .03 \\
\hline Dance/House & -.01 & -.05 & .10 & -.03 & .10 & .09 & .05 & .11 \\
\hline Techno & .07 & .04 & .05 & -.05 & .09 & .12 & .07 & .06 \\
\hline Hardhouse & .09 & .06 & $.12 *$ & .03 & $.27 * *$ & $.24 * *$ & $.20 * *$ & $.32 * *$ \\
\hline Classic music & -.11 & -.09 & .02 & -.04 & -.08 & $-.23 * *$ & -.10 & $-.19 * *$ \\
\hline \multicolumn{9}{|l|}{ Internet surfing } \\
\hline Fun & .03 & $-.19 * *$ & .05 & $-.19 * *$ & -.01 & -.04 & .04 & -.04 \\
\hline Info & -.07 & -.04 & .09 & -.06 & -.03 & $-.19 * *$ & -.06 & $-.15^{*}$ \\
\hline Music & .04 & .05 & .04 & .05 & .04 & $.17 * *$ & .08 & .11 \\
\hline Erotica & $.44 * *$ & $.29 * *$ & $.43 * *$ & -.04 & $.45 * *$ & .11 & $.34 * *$ & .06 \\
\hline \multicolumn{9}{|l|}{ Internet chatting } \\
\hline Friends & -.08 & .07 & .02 & -.01 & .00 & .12 & .10 & $.18^{*}$ \\
\hline New friends & .07 & .10 & .00 & -.03 & -.01 & .08 & .10 & .10 \\
\hline Romantic partners & $.30 * *$ & .11 & $.19 * *$ & .07 & $.26 * *$ & $.17^{*}$ & $.25 * *$ & .04 \\
\hline
\end{tabular}

ment of sexual attitudes and stereotypes, the structure of the association between music factors and attitudes and stereotypes was highly identical.

\section{Hypotheses Confirmed?}

Although corroborated in the correlational analysis, the first hypothesis, more frequent exposure to youth media relates to higher SAS, was not relevant when modeling these relations in SEM. In SEM, exposure to TV, music/music videos, and internet did not survive as an important indicator, implying that media preferences are more important than media exposure with regard to predicting SAS. Partial support was found for the second hypothesis, preferences for specific media types-music videos, heavy metal, and hip-hop music-are linked to stronger enhancement of permissive sex and stereotypical gender-role attitudes, when other factors are controlled. In the final SEM model, liking hip-hop emerged as a highly significant indicator of SAS, in addition to, unexpectedly, hard-house music and classic music. Furthermore, more evidence was found for the soundness of the third hypothesis that preferences for sexually explicit TV or internet content are the strongest indicator of permissive sex and stereotypical 
Table 4 Standardized path coefficients between person characteristics, music preferences, internet use, and sexual attitudes and stereotypes.

\begin{tabular}{|c|c|c|c|c|c|c|c|c|c|c|}
\hline & \multicolumn{2}{|l|}{ Person } & \multicolumn{4}{|l|}{ Media } & \multicolumn{4}{|c|}{ Attitudes and stereotypes } \\
\hline & $\begin{array}{l}\text { Sens. } \\
\text { seeking }\end{array}$ & $\begin{array}{l}\text { Sex. } \\
\text { Exp. }\end{array}$ & $\begin{array}{l}\text { Hip-hop } \\
\text { music }\end{array}$ & $\begin{array}{l}\text { Hard house } \\
\text { music }\end{array}$ & $\begin{array}{l}\text { Classic } \\
\text { music }\end{array}$ & $\begin{array}{l}\text { Internet } \\
\text { erotica }\end{array}$ & $\begin{array}{l}\text { Casual } \\
\text { sex OK }\end{array}$ & $\begin{array}{l}\text { Men sex } \\
\text { driven }\end{array}$ & $\begin{array}{l}\text { Women } \\
\text { objects }\end{array}$ & $\begin{array}{l}\text { Men } \\
\text { tough }\end{array}$ \\
\hline \multicolumn{11}{|l|}{ Person } \\
\hline $\begin{array}{l}\text { Gender } \\
(\text { male }=0)\end{array}$ & $-.25^{* * *}$ & $-.32 * * *$ & $.09 *$ & - & - & $-.59 * * *$ & $-.12 *$ & $.28 * * *$ & $-.21 * * *$ & - \\
\hline Education & - & - & - & $-.20 * * *$ & $.13^{* *}$ & $.10^{* *}$ & $.15 * * *$ & - & - & - \\
\hline $\begin{array}{l}\text { Sensation } \\
\text { Seeking }\end{array}$ & $.37 * * *$ & - & - & $.13 * *$ & $-.10^{*}$ & $.32 * * *$ & $.13 * *$ & - & - & - \\
\hline $\begin{array}{l}\text { Sexual } \\
\text { Experience }\end{array}$ & - & $.37 * * *$ & - & - & - & $.57 * * *$ & $.32 * * *$ & $.23 * * *$ & $.17^{* *}$ & $.20 * *$ \\
\hline \multicolumn{11}{|l|}{ Media: Music } \\
\hline Hip-hop & - & - & - & - & - & - & - & - & $.12 * *$ & $.14 * *$ \\
\hline Hardhouse & $.13 * *$ & - & - & - & - & - & - & - & $.19 * * *$ & $.27 * * *$ \\
\hline $\begin{array}{l}\text { Classic } \\
\text { music }\end{array}$ & $-.10^{*}$ & - & - & - & - & - & - & - & $-.15^{* * *}$ & $-.14 * *$ \\
\hline \multicolumn{11}{|c|}{ Media: Internet } \\
\hline Erotica & $.32 * * *$ & $.57 * * *$ & - & - & - & - & $.31 * * *$ & $.36 * * * /-.03$ & $.27 * * *$ & $.15^{*}$ \\
\hline
\end{tabular}

Path coefficients in columns 2-7 refer to connections between predictors, and in columns $8-11$ to paths between predictors and outcomes;-indicates no significant relation.

Bold typeface signifies significant difference between boys and girls as indicated by an increase in model fit of the multigroup model when releasing constraints; $\Delta \mathrm{CMIN}=9.39, p<.01$; path coefficients: boys $.36^{* * *}$; girls -.03 n.s.

gender-role attitudes when other factors are controlled. Liking sexually explicit TV did not survive in the final analysis; however, preference for sexually charged internet content surfaced as a highly relevant marker of SAS, particularly among boys.

\section{Discussion}

\section{Associations Between MEP and SAS}

The first research question pertained to whether media exposure and preferences were linked to SAS and the answer is straightforward: Yes. Youth TV has been characterized as high on sexual content (cf. EscobarChaves et al. 2005; Ward 2003) and results from correlational analysis indicated that, particularly for girls, high levels of overall TV exposure were linked to higher approval of permissive sex and stronger stereotyping. On the basis of preference ratings for different programs, it could be further specified which content was typically related to SAS. For girls, preferring soap operas and romantic movies related to endorsing stereotypes. Among boys, liking romantic movies was linked with positively evaluating permissive sex and believing that men are sexdriven. Furthermore, boys' preference for sports and, more so, erotic TV content were associated relatively strongly to SAS.
In addition to TV, pop music and music TV are known for their frequent references to romance, flirting, and sex (cf. Arnett 2002). The current correlational results indicated that high exposure to music and music TV was associated with approval of permissive sex. By analyzing preferences, these researchers determined which types of music were related to SAS and found that preferring hip-hop, R\&B, and the loudest, most energetic forms of electronic dance and hard-house music, were connected positively to SAS, particularly to ideas that women should look sexy and men cool and tough. In contrast, liking classic music was negatively associated to stereotyping.

The internet is the latest and potentially the most important provider of explicit sexual content (cf. Lo and Wei 2005; Peter and Valkenburg 2006a). High exposure to this new media environment, particularly for girls, positively correlated with SAS. As for boys, several types of internet use (i.e., chatting with potential romantic partners and searching for erotic content), strongly and positively correlated to endorsing sexual attitudes and stereotypes. The opposite seemed to hold for girls' surfing for fun or to find information on the internet. These activities were more often negatively associated to attitudes and stereotypes.

\section{The Strongest Media Indicators of SAS}

The second research question pertained to uncovering the strongest markers of SAS. In the current SEM models, all 
media exposure factors that were significant in the correlational analysis disappeared as significant indicators and only some preference scores appeared as relevant indicators. Therefore, we conclude that media preferences are more important indicators of SAS than exposure per se. Peter and Valkenburg (2007) suggested a hierarchical pattern in the relationship between media factors and SAS. They found preferences for explicit erotic content as a far more potent correlate of the notion of women as sex objects compared to less explicit material. The current results support their view; specifically, preference for explicit erotic internet content was the single most important media marker of SAS, particularly among boys. Hence, more evidence was found for the idea that this new media environment, with its easily accessible, explicit, and even pornographic content may be a more powerful socializing agent than references to sex in traditional media (Donnerstein and Smith 2001; Lo and Wei 2005; Peter and Valkenburg 2006b, 2007).

It is interesting that besides a penchant for internet erotica, preferences for several types of music were linked to attitudes and stereotypes. In the final model, liking hiphop and hard-house music was positively associated to particular gender stereotypes and preferring classical music was negatively associated. As noted, some forms of hip-hop music have become notorious, as the videos to this music are often characterized by their stereotypical portrayal of females as sexual objects (Ter Bogt 2007). Current results concerning liking hip-hop, a genre fraught with stereotypical images of gender roles, was connected to stronger endorsements of SAS. Content analysis of electronic dance music and its dominant media imaginary is not yet available. However, research has indicated that house music is the centre of a youth culture that has sensual and hedonistic features. House music is, by definition, connected to nightlife; that is, looking smart and sexy, going out, dancing, and flirting (Reynolds 1999). Hence, the link between liking (hard) house music and SAS may not come as a surprise. It is furthermore telling that a preference for music that has no association with partying, such as classical music, was negatively connected to stereotypes. Music that is not youth cultural in origin, generally unpopular among adolescents, and framed as music for adults (Mulder et al. 2007) was marking less stereotyping. It seems that young people preferring this type of music perceive the world as less dependent on physical looks.

It is also interesting to note that some genres that have a bad reputation in regard to highly charged sexy portrayal of females were not connected (any more) to SAS. Throughout the $80 \mathrm{~s}$ and $90 \mathrm{~s}$, heavy metal was characterized as a violent and misogynic music genre (Ter Bogt 2007); however, in current data no link was found between preferring heavy metal and SAS. Over the last two decades, the audience for loud forms of rock music has been feminized and it seems that, with this change in audience, the music itself has cast off its misogynist shell. At least in the Netherlands a rather fairy-tale-like, romantic type of Gothic, with bands fronted by female singers, attracts a predominantly younger, female audience (Ter Bogt et al. 2003).

Gender Differences in the Associations between MEP and SAS

The third research question pertained to potential gender differences in the paths between MEP and SAS. One of the most striking results of the current structural analysis was that similar links were found between music preferences and SAS among girls and boys. Liking hip-hop, hardhouse, or classic music, both girls and boys, to the same degree, tended to either enhance or reject SAS. One association between media and SAS appeared to be clearly specific for boys, when preferring erotic content, boys more often tended to think of men as sex-driven, while girls did not report these beliefs. This result implies that, for boys, explicit sexual content found on the internet may contribute to the development of gender stereotypes, particularly with regard to the norm of having to be or wanting to be a potent, sexually, insatiable men.

Other important gender differences become apparent when the intensity of exposure to different media types is taken into account. Girls were more inclined to prefer and listen to hip-hop and R\&B music; hence, they are more often exposed to the well-documented stereotypical portrayal of gender roles in the lyrics and music videos. Even more so than for boys, music may be a key source of SAS for girls. On the other hand, boys seek to expose themselves far more often to explicit erotic content and, for this group, the internet may be more important in shaping SAS.

In sum, first, music appears to affect audiences in similar ways; however, explicit internet content may affect boys more than girls, and, second, as structural differences in the tendency to seek exposure to different media exist, for boys, erotic content, and, for girls, popular music, may be more relevant for shaping SAS.

\section{Limitations}

The current research defined adolescent media users as actively searching for TV, music, and internet content that fits them. It is assumed that preferences drive media exposure and that watching or listening to content may further shape attitudes. However, we do not know if adolescents preferring specific types of media content indeed watched and listened more frequently and whether 
they were affected by consumption of the preferred content. This relates to another limitation of this study; its crosssectional design. Sexualized media may indeed reinforce the endorsement of permissive ideas, the characterizing of males as sex-driven, and views that sexiness for girls and toughness for boys are all-important, but it is also probable that adolescents in favor of permissive sex and stereotypical attitudes are drawn to content that reflects these ideas, or that a third variable, personality, parent/family environment factors, and peer group culture, drives both media choices and sexual attitudes. We found connections between media preferences and sexual attitudes; however, the current design obstructed identifying the (potential) causal direction of these links. While the idea that exposure to, for example, strong sexual images in internet erotica, and to rigid stereotypical portrayal of men and women in gangsta rap music videos may directly shape SAS has face value, it is more difficult to imagine that preferring Bach's Chorales or Chopin's Etudes may influence sexual attitudes and stereotypes. Correlation analyses cannot discern between causal influences or selection effects. It must be noted that experimental research in which adolescents are confronted with more or less explicit content, capable of solving the causality issue, is hindered by ethical considerations. A longitudinal study of the development of both media use and sexual attitudes is necessary in order to further explore evidence of real influences of media on SAS. Longitudinal research, or assessing over time those connections between media exposure and SAS, has been to date scarce (Peter and Valkenburg 2008a). The current results may at least direct future research in choosing which formats to study in a longitudinal context.

\section{Conclusion}

The study of youth media content and its effects is important. As a significant socializing context, media should contribute to positive psychosocial adolescent development. Becoming comfortable with a changing body form and image and learning how to deal with friendships, romance, and sexuality are all important developmental tasks during this life-phase. Heavy exposure to music/music TV, glorifying sexiness and toughness, may endorse ideas that looks are all-important. Though a plethora of social scientific research has indicated that appearance indeed counts socially, research has also noticed that overemphasizing looks may have negative consequences. Self-objectification theory (Fredrickson and Roberts 1997) posits that people who are preoccupied with appearance solidify a self-objectified point of view of their own body and self-objectification, in turn, increases the opportunity for negative emotions such as shame and anxiety and contributes to a variety of mental and physical problems, such as eating disorders, sexual dysfunction, and depression.
In addition, we found that adolescents, particularly boys, searching for erotica endorsed SAS. Heavy exposure to explicit content at an age when young people are beginning to explore their emerging sexual longings and defining which attitudes and behavior fit them, may provide them with a rather unrealistic picture of sexual relationships and behaviors. With a focus on lust and portrayal of sex as a merely physical act between uncommitted partners, the internet's pornographic content may give an instantly titillating but rather limited account of human sexuality.

In our opinion youth media should not shy away from themes that are of utmost importance during adolescence. When Elvis started gyrating his hips in the fifties, a behavior that gained him the nickname "Pelvis," his performance was deemed overly sexual and obscene. Worried parents, educators, and entertainment industry executives, pressured TV channels to have him filmed from his waist up, when performing on TV. Probably not even staunch conservatives would want to go back to this type of censorship; however, with a media environment that has seen profound changes and the advent of highly explicit internet materials, only a few clicks away at the hands of nearly all adolescents, the discussion on what young people should be exposed to and on how to educate teenagers to use media in a sensible and healthy way has gained new urgency. To date. much research, including the current investigation, has focused on the potential negative effects of media exposure. More research is needed on media formats that gratify the adolescent fascination for "forbidden fruits," but deter rigid stereotyping and help develop a positive and healthy body image and sexual identity.

Open Access This article is distributed under the terms of the Creative Commons Attribution Noncommercial License which permits any noncommercial use, distribution, and reproduction in any medium, provided the original author(s) and source are credited.

\section{References}

Arbuckle, J. L. (2006). Amos 7.0 User's Guide. Chicago: SPSS.

Arnett, J. (1996). Metalheads: Heavy metal music and adolescent alienation. Boulder: Westview.

Arnett, J. J. (2002). The sounds of sex: Sex in teens' music and music video's. In J. D. Brown, J. R. Steele, \& K. Walsh-Childers (Eds.), Sexual teens, sexual media: Investigating media's influence on adolescent sexuality (pp. 253-264). Mahwah: Lawrence Erlbaum.

Aubrey, J. S. (2006). Exposure to sexually objectifying media and body self-perceptions among college women: An examination of the selective exposure hypothesis and the role of moderating variables. Sex Roles, 55, 159-172.

Aubrey, J. S., Harrison, K., Kramer, L., \& Yellin, J. (2003). Variety versus timing-Gender differences in college students' sexual expectations as predicted by exposure to sexually oriented television. Communication Research, 30, 432-460. 
Bandura, A. (1986). Social foundations of thought and action: A social cognitive theory. Englewood Cliffs: Prentice-Hall.

Baxter, R. L., De Riemer, C., Landini, A., Leslie, L., \& Singletary, M. W. (1985). A content analysis of music videos. Journal of Broadcasting and Electronic Media, 29, 333-340.

Bem, S. L. (1981). Gender schema theory: A cognitive account of sex typing. Psychological Review, 88, 354-364.

Borzekowski, D., Robinson, T., \& Killen, J. (2000). Does the camera add 10 pounds? Media use, perceived importance of appearance, and weight concerns among teenage girls. Journal of Adolescent Health, 26, 36-41.

Braun-Courville, D. K., \& Rojas, M. (2009). Exposure to sexually explicit web sites and adolescent sexual attitudes and behaviors. Journal of Adolescent Health, 45, 156-162.

Brown, J. D., Halpern, C. T., \& L'Engle, K. L. (2005). Mass media as a sexual super peer for early maturing girls. Journal of Adolescent Health, 36, 420-427.

Brown, J. D., L'Engle, K. L., Pardun, C. J., Guo, G., Kenneavy, K., \& Jackson, C. (2006). Sexy media matter: Exposure to sexual content in music, movies, television, and magazines predicts black and white adolescents' sexual behavior. Pediatrics, 117, 1018-1027.

Brown, J. D., \& Pardun, C. J. (2004). Little in common: Racial and gender differences in adolescents' TV diets. Journal of Broadcasting and Electronic Media, 48, 266-278.

Bryant, J., \& Rockwell, S. C. (1994). Effects of massive exposure to sexually oriented prime time television on adolescents' moral judgment. In J. Bryant \& S. C. Rockwell (Eds.), Media, children, and the family: Social scientific, psychodynamic, and clinical perspectives (pp. 183-195). Hillsdale: Lawrence Erlbaum.

Calfin, M. S., Carroll, J. L., \& Schmidt, J. (1993). Viewing music-video tapes before taking a test of premarital sexual attitudes. Psychological Reports, 72, 475-481.

Carpentier, F. D., Knobloch-Westerwick, S., \& Blumhoff, A. (2007). Naughty versus nice: Suggestive pop music influences on perceptions of potential romantic partners. Media Psychology, 9, 1-17.

Carroll, J., Padilla-Walker, L., Nelson, L., Olson, C., McNamara Barry, C., \& Madsen, S. (2008). Generation XXX: Pornography acceptance and use among emerging adults. Journal of Adolescent Research, 23, 6-30.

Christenson, P. G., Roberts, D. F., Strange, J., \& Wild, D. (2004). Primetime teens: perspectives on the new youth-media environment [Electronic Version]. Retrieved from http://www.wtgrantfoundation. org/usr doc/PrimeTimeMediascope2004.pdf.

Collins, R. L., Elliott, M. N., Berry, S. H., Kanouse, D. E., Kunkel, D., Hunter, S. B., et al. (2004). Watching sex on television predicts adolescent initiation of sexual behavior. Pediatrics, 114, 280 289

De Graaf, H., Meijer, S., Poelman, J., \& Van Wesenbeeck, I. (2005). Seks onder je 25e. Seksuele gezondheid van jongeren in Nederland anno 2005 [Sex before the 25th birthday. Sexual health of youth in the Netherlands in 2005]. Utrecht: NISSO.

Donnerstein, E., \& Smith, S. L. (2001). Sex in the media: Theory, influences, and solutions. In D. G. Singer \& J. L. Singer (Eds.), Handbook of children and the media (pp. 289-307). Thousand Oaks: Sage.

Dukes, R. L., Bisel, T. M., Borega, K. N., Lobato, E. A., \& Owens, M. D. (2003). Expressions of love, sex, and hurt in popular songs: a content analysis of all-time greatest hits. Social Science Journal, 40, 643-650.

Eggermont, S. (2006). The impact of television viewing on adolescents' sexual socialization (Doctoral dissertation). Leuven: K.U. Leuven.

Escobar-Chaves, S. L., Tortolero, S. R., Markham, C. M., Low, B. J., Eitel, P., \& Thickstun, P. (2005). Impact of the media on adolescent sexual attitudes and behaviors. Pediatrics, 116, 303326.
Fredrickson, B. L., \& Roberts, T. A. (1997). Objectification theoryToward understanding women's lived experiences and mental health risks. Psychology of Women Quarterly, 21, 173-206.

Gadassi, R., \& Gati, I. (2009). The effect of gender stereotypes on explicit and implicit career preferences. Counseling Psychologist, 37, 902-922.

Götz, M., Hofmann, O., Brosius, H., Carter, C., Chan, K., Donald, S., et al. (2008). Gender in children's television worldwide. Results from a media analysis in 24 countries. TelevIZIon, 21, 4-9.

Greenberg, B. S., \& Busselle, R. W. (1996). Soap operas and sexual activity: A decade later. Journal of Communication, 46, 153-160.

Greeson, L. E., \& Williams, R. A. (1986). Social implications of music videos on youth: An analysis of the content and effects of MTV. Youth and Society, 18, 177-189.

Handelsman, C. D., Cabral, R. J., \& Weisfield, G. E. (1987). Sources of information and adolescent sexual knowledge and behavior. Journal of Adolescent Research, 2, 455-466.

Hansen, C. H., \& Hansen, R. (1988). How rock music videos can change what's seen when boy meets girl: Priming stereotypical appraisal of social interaction. Sex Roles, 19, 287-316.

Hansen, C. H., \& Krygowski, W. (1994). Arousal-augmented priming effects - rock-music videos and sex object schemas. Communication Research, 21, 24-47.

Hawk, S. T., Vanwesenbeeck, I., De Graaf, H., \& Bakker, F. (2006). Adolescents' contact with sexuality in mainstream media: A selection-based perspective. Journal of Sex Research, 43, 352-363.

Herd, D. (2005). Changes in the prevalence of alcohol use in rap song lyrics, 1979-97. Addiction, 100, 1258-1269.

Hofstede, G. (2001). Culture's consequences: Comparing values, behaviors, institutions, and organizations across nations. Thousand Oaks: Sage.

Hoyle, R. H., Stephenson, M. T., Palmgreen, P., Lorch, E. P., \& Donohew, R. L. (2002). Reliability and validity of a brief measure of sensation seeking. Personality and Individual Differences, 32, 401-414.

Hu, L., \& Bentler, P. M. (1999). Cutoff criteria for fit indexes in covariance structure analysis: Conventional criteria versus new alternatives. Structural Equation Modeling, 6, 1-55.

Hust, S. J. T., Brown, J. D., \& L'Engle, K. L. (2008). Boys will be boys and girls better be prepared: An analysis of the rare sexual health messages in young adolescents' media. Mass Communication and Society, 11, 3-23.

Huston, A. C., Wartella, E., \& Donnerstein, E. (1998). Measuring effects of sexual content in the media: A report to the Kaiser Family Foundation. Washington DC: The Henry J. Kaiser Family Foundation.

Jo, E., \& Berkowitz, L. (1994). A priming effect analysis on media influences: An update. In J. Bryant \& D. Zillman (Eds.), Media effects: Advances in theory and research (pp. 43-60). Hillsdale: Erlbaum

Kalof, L. (1999). The effects of gender and music video imagery on sexual attitudes. Journal of Social Psychology, 139, 378-385.

Kim, J. L., Collins, R. L., Kanouse, D. E., Elliott, M. N., Berry, S. H., Hunter, S. B., et al. (2006). Sexual readiness, household policies, and other predictors of adolescents' exposure to sexual content in mainstream entertainment television. Media Psychology, 8, 449-471.

Kunkel, D., Biely, E., Eyal, K., Cope-Farrar, K., Donnerstein, E., \& Fandrich, R. (2003). Sex on TV: A biennal report to the Kaiser Family Foundation. Menlo Park: The Henry J. Kaiser Family Foundation.

Lam, C., \& Chan, D. (2007). The use of pornography by young men in Hong Kong: Some psychosocial correlates. Archives of Sexual Behavior, 36, 588-598.

L'Engle, K. L., Brown, J. D., \& Kenneavy, K. (2006). The mass media are an important context for adolescents' sexual behavior. Journal of Adolescent Health, 38, 186-192. 
Lo, V. H., \& Wei, R. (2005). Exposure to Internet pornography and Taiwanese adolescents' sexual attitudes and behavior. Journal of Broadcasting \& Electronic Media, 49, 221-237.

Lowry, D. T., \& Shilder, J. A. (1993). Prime time TV portrayals of sex, "safe sex", AIDS: A Longitudinal analysis. Journalism Quarterly, 70, 628-637.

Martino, S. C., Collins, R. L., Elliott, M. N., Strachman, A., Kanouse, D. E., \& Berry, S. H. (2006). Exposure to degrading versus nondegrading music lyrics and sexual behavior among youth. Pediatrics, 118, E430-E441.

Martino, S. C., Collins, R. L., Kanouse, D. E., Elliott, M., \& Berry, S. H. (2005). Social cognitive processes mediating the relationship between exposure to television's sexual content and adolescents' sexual behavior. Journal of Personality and Social Psychology, 89, 914-924.

Mulder, J., Ter Bogt, T., Raaijmakers, Q., \& Vollebergh, W. (2007). Adolescent music preferences and problem behavior. Journal of Youth and Adolescence, 36, 313-324.

Mundorf, N., D’Alessio, D., Allen, M., \& Emmers-Sommer, T. M. (2006). Effects of pornography. In R. W. Preiss, B. M. Gayle, N. Burrell, M. Allen, \& J. Bryant (Eds.), Mass media effects research: Advances through meta-analysis (pp. 173-189). Mahwah: Erlbaum.

Murnen, S. K., Wright, C., \& Kaluzny, G. (2002). If "Boys will be boys," then girls will be victims? A meta-analytic review of research that relates masculine ideology to sexual agression. Sex Roles, 46, 2002.

Mustanski, B. S. (2001). Getting wired: Exploiting the internet for collecting sexually valid data. Journal of Sex Research, 38, 292-301.

North, A. C., Hargreaves, D. J., \& O'Neill, S. A. (2000). The importance of music to adolescents. British Journal of Educational Psychology, 70, 255-272.

Pardun, C. J., L'Engle, K. L., \& Brown, J. D. (2005). Linking exposure to outcomes: Early adolescents' consumption of sexual content in six media. Mass Communication and Society, 8, 75-91.

Peter, J., \& Valkenburg, P. M. (2006a). Adolescents' exposure to sexually explicit material on the internet. Communication Research, 33, 178-204.

Peter, J., \& Valkenburg, P. M. (2006b). Adolescents' exposure to sexually explicit online material and recreational attitudes toward sex. Journal of Communication, 56, 639-660.

Peter, J., \& Valkenburg, P. M. (2007). Adolescents' exposure to a sexualized media environment and their notions of women as sex objects. Sex Roles, 51, 381-395.

Peter, J., \& Valkenburg, P. M. (2008a). Adolescents' exposure to sexually explicit Internet material and sexual preoccupancy: A three-wave panel study. Media Psychology, 11, 207-234.

Peter, J., \& Valkenburg, P. M. (2008b). Adolescents' exposure to sexually explicit Internet material, sexual uncertainty, and attitudes toward uncommitted sexual exploration: Is there a link? Communication Research, 35, 579-601.

Peter, J., \& Valkenburg, P. M. (2009). Adolescents' exposure to sexually explicit internet material and notions of women as sex objects: Assessing causality and underlying processes. Journal of Communication, 59, 407-433.

Reynolds, S. (1999). Generation Ecstasy: Into the world of techno and rave culture. London: Taylor and Francis.

Sapolsky, B. S., \& Tabarlet, J. O. (1991). Sex in prime-time television -1979 versus 1989. Journal of Broadcasting \& Electronic Media, 35, 505-516.

Sherman, B. L., \& Dominick, J. R. (1986). Violence and sex in music videos: TV and rock 'n' roll. Journal of Communication, 36, 79-93.

Sikkema, P. (2005). Jongeren 2005 [Youth 2005]. Amsterdam: Qrius Research.
Sikkema, P. (2007). Jongeren 2007 [Youth 2007]. Amsterdam: Qrius Research.

Smolak, L., \& Stein, J. A. (2006). The relationship of drive for muscularity to sociocultural factors, self-esteem, physical attributes gender role, and social comparison in middle school boys. Body Image, 3, 121-129.

SPOTtime. (2008). Tijdbestedingscijfers jeugd 2008 [Youth's time budget 20087. Amstelveen: Stichting SPOT.

Steele, J. R., \& Brown, J. D. (1995). Adolescent room culture: Studying media in the context of everyday life. Journal of Youth and Adolescence, 24, 551-576.

Strasburger, V. C., \& Donnerstein, E. (1999). Children, adolescents, and the media: Issues and solutions. Pediatrics, 103, 129-139.

Strouse, J. S., Buerkelrothfuss, N., \& Long, E. C. J. (1995). Gender and family as moderators of the relationship between Music Video Exposure and Adolescent Sexual Permissiveness. Adolescence, 30, 505-521.

Sutton, M. J., Brown, J. D., Wilson, K. M., \& Klein, J. D. (2002). Shaking the tree of knowledge for forbidden fruit: Where adolescents learn about sexuality and contraception. In J. D. Brown, J. R. Steele, \& K. Walsh-Childers (Eds.), Sexual teen, sexual media (pp. 25-55). Mahwah: Lawrence Erlbaum Associates.

Ter Bogt, T. (2000). De geschiedenis van jeugdcultuur en popmuziek.[On the history of youth culture and pop music]. In T. Ter Bogt \& B. Hibbel (Eds.), Wilde jaren: een eeuw jeugdcultuur [Wild years: A century of youth culture] (pp. 27-151). Utrecht: Lemma.

Ter Bogt, T. F. M. (2007). Parents Music Resource Center (PMRC). In J. J. Arnett (Ed.), Encyclopedia of children, adolescents and the media (Vol. 2, pp. 644-645). Thousand Oaks: Sage.

Ter Bogt, T., Raaijmakers, Q., Vollebergh, W., Van Wel, F., \& Sikkema, P. (2003). Youngsters and their musical taste. Musical styles and taste groups. Netherlands' Journal of Social Sciences, $39,35-52$.

Ward, L. M., \& Rivadeneyra, R. (1999). Contributions of entertainment television to adolescents' sexual attitudes and expectations: The role of viewing amount versus viewer involvement. Journal of Sex Research, 36, 237-249.

Ward, L. M. (2002). Does television exposure affect emerging adults' attitudes and assumptions about sexual relationships? Correlational and experimental confirmation. Journal of Youth and Adolescence, 31, 1-15.

Ward, L. M. (2003). Understanding the role of entertainment media in the sexual socialization of American youth: A review of empirical research. Developmental Review, 23, 347-388.

Ward, L. M., \& Friedman, K. (2006). Using TV as a guide: Associations between television viewing and adolescents' sexual attitudes and behavior. Journal of Research on Adolescence, 16, $133-156$

Ward, L. M., Hansbrough, E., \& Walker, E. (2005). Contributions of music video exposure to black adolescents' gender and sexual schemas. Journal of Adolescent Research, 20, 143-166.

Ward, L. M., Merriwether, A., \& Caruthers, A. (2006). Breasts are for men: Media, masculinity ideologies, and men's beliefs about women's bodies. Sex Roles, 55, 703-714.

Weinstein, D. (2000). Heavy metal: The music and its culture (revised edition). New York: Da Capo.

Wolak, J., Mitchell, K., \& Finkelhor, D. (2007). Unwanted and wanted exposure to online pornography in a national sample of youth internet users. Pediatrics, 119, 247-257.

Zurbriggen, E. L., \& Morgan, E. M. (2006). Who wants to marry a millionaire? Reality dating television programs, attitudes toward sex, and sexual behaviors. Sex Roles, 54, 1-17. 